\title{
Cibernética e Ficção Científica: uma proposta pedagógica
}

\section{Cybernetics and Science Fiction: a pedagogical proposal}

\author{
Viviane Hengler Corrêa Chaves*
}

\begin{abstract}
Resumo
A Cibernética, no mundo atual, desperta algumas formulações de ordem conceitual sobre o homem e sobre a sua realidade tecnológica artificial que o transporta para um mundo de condições sobre-humanas, um mundo ficcional. Neste mundo, a Matemática exerce papel relevante, sua lógica e sua precisão são recursos utilizados para tornar os fatos mais convincentes. Grande parte das obras ficcionais pode ser utilizada como material didático para o ensino de variadas ciências, despertando no estudante a curiosidade por temáticas que nem sempre estão disponíveis em conteúdos curriculares, como é o caso da inteligência artificial e da própria Cibernética. Muitas pesquisas acadêmicas bem sucedidas foram influenciadas por obras de ficção científica. Nessa direção, compõe este artigo, um conto de ficção científica, intitulado "Bioboy, o Ciborgue que calculava", fazendo alusão ao livro de Malba Tahan, "O homem que calculava”. O objetivo do conto é ilustrar os impactos da Cibernética e das ciências decorrentes desta na sociedade.
\end{abstract}

Palavras-chave: Cibernética, Ficção Científica, Matemática.

\begin{abstract}
Cybernetics, in the world nowadays, awakens some conceptual formulations about men and the artificial technological reality that transports them to a world of superhuman conditions, a fictional world. In this world, Mathematics plays a relevant role, its logic and its precision are resources used to make the facts more convincing. Most of the fictional works can be used as teaching material of various sciences, arousing in the student's mind a curiosity for topics that are not always available in curricular contents, such as artificial intelligence and Cybernetics. Many successful researches were influenced by works of science fiction. According to this point of view, this paper also brings a science-fiction tale entitled "Bioboy, the Cyborg who calculated," alluding to Malba Tahan's book, "The Man Who Calculated." The purpose of the story is to illustrate the impacts of cybernetics and the sciences arising from it, in society.
\end{abstract}

Keywords: Cybernetics, Science Fiction, Mathematics

\section{Ficção científica}

É comum as pessoas associarem os termos cibernética e ciborgue à ficção científica, atribuindo à primeira ares de ficção. Para o censo comum, a cibernética e a ficção científica apresentam uma relação íntima de entendimento, ou seja, a cibernética é um ponto de referência para a ficção. Entretanto, apesar das conceituações apresentarem diferenças, os termos são comumente confundidos devido a sua forte inter-relação.

\footnotetext{
* Doutorado em Educação Matemática pela UNESP. Professora Substituta na UNESP, Rio Claro, SP, Brasil. Endereço para correspondência: Rua Miguel Petroni, 4900, casa 184 Condomínio Eldorado, Loteamento Habitacional São Carlos 1, São Carlos, SP, Brasil, CEP: 13563-470. E-mail: viviane.hcc@ bol.com.br.
} 
Não existe uma definição unânime para ficção científica. A maioria dos dicionários reconhece a ficção científica como uma criação de caráter artístico, baseada na imaginação, dos progressos científicos e tecnológicos. Alguns, grandes nomes da literatura desse gênero, a definem como:

\begin{abstract}
Asimov (1984), por exemplo, a insere em um gênero mais geral - a ficção surrealista - que retrataria "fatos que se verificam em ambientes sociais não existentes na atualidade e que jamais existiram em épocas anteriores". Na FC, em particular, tais fatos "podem ser concebivelmente derivados do nosso próprio meio social, mediante adequadas mudanças ao nível da ciência e da tecnologia" (p. 16). Para Allen (1976), a FC distingue-se "de outros tipos de ficção pela presença de uma extrapolação dos efeitos humanos de uma ciência extrapolada" (p. 235). Entendemos a ciência extrapolada de Allen como uma categoria que engloba qualquer forma de utilização de ideias científicas para a produção do conteúdo veiculado no texto, ou seja, ela não é o conteúdo em si, mas uma diretriz para sua construção. Umberto Eco (1989) se aproxima de Asimov ao propor que, na FC, "a especulação contrafactual de um mundo estruturalmente possível é conduzida extrapolando, de algumas linhas de tendência do mundo real, a possibilidade mesma do mundo futurível", e também de Allen ao enfatizar o aspecto de antecipação da FC que, segundo ele, "assume a forma de uma conjetura formulada a partir de linhas de tendência reais do mundo real" (p. 169, grifos do autor). A antecipação, fundada na racionalidade científica, serve assim a uma especulação a respeito do mundo real. Para o autor, [...] a boa ficção científica é cientificamente interessante não porque fala de prodígios tecnológicos [...], mas porque se apresenta como um jogo narrativo sobre a própria essência de toda a ciência, isto é, sobre a sua conjeturabilidade (p. 170) (PIASSI; PIETROCOLA, 2009, p. 527-528).
\end{abstract}

O desenvolvimento científico e tecnológico cria um universo de possibilidades, cada vez maior, sobre o qual é possível extrair matéria de ficção e esta, por sua vez, explora o impacto que essas tecnologias podem exercer sobre as sociedades e os indivíduos.

Asimov (1920-1992), um dos principais autores desse gênero, não tem medo de ter uma ideia e persegui-la até torná-la interessante e declara que a ficção científica é "a única literatura de ideias relevantes" (BRANTLINGER, 1980, p. 38, tradução nossa) ${ }^{1}$. Cabe, aqui, ressaltar, sua habilidade em explicar, com um pouco de aritmética ou álgebra, suas ideias ficcionais.

A dependência excessiva dos humanos pelas máquinas tornou-as um marco da ficção científica na mídia impressa, novelas e no cinema. Na década de 1930, a cultura popular apropriou-se do termo robô para identificar as máquinas pensantes que substituem os humanos em todas as suas atividades. O computador, fictício na época, tornou-se cérebro desses seres, comumente tidos como homens mecânicos feitos de metal. Os computadores e os robôs são figurantes antigos do nosso imaginário e de Isaac Asimov, que escreveu

\footnotetext{
1 "the only literature of relevant ideas".
} 
inúmeros contos sobre eles, destaque para "I, Robot" publicado em 1950, nos quais apresentou as lendárias leis ${ }^{2}$ da robótica.

A ficção científica começa a ganhar espaço e a tornar-se uma categoria significativa no final do século XIX, com as obras de Júlio Verne (1828-1905) e Herbert George Wells (1866-1946). "Enquanto Verne produzia histórias para maravilhar os leitores com as possibilidades de um futuro excitante, Wells empregava a fantasia científica para a crítica social” (PIASSI; PIETROCOLA, 2009, p. 527).

Júlio Verne escreveu histórias de viagens fantásticas, tais como "Viagem ao Centro da Terra", publicada em 1863. A alta tecnologia esteve presente em suas obras, representada pelo submarino Nautilus em “20.000 Léguas submarinas”, ou a cápsula tripulada, descrita em sua obra "Da Terra à Lua", escrita em 1865. A cápsula, arremessada por um canhão com destino à Lua, antecipava os foguetes e as viagens espaciais. Talvez, essa seja a obra mais visionária de Júlio Verne, escrita cem anos antes de o homem chegar à Lua.

Wells também escreveu histórias sobre a exploração lunar, "Os Primeiros Homens na Lua“, de 1901. Nesse romance, um cientista inventa um metal que resiste à gravidade e, com ele, é possivel construir uma esfera no interior da qual as pessoas podem flutuar sobre a Terra e viajar rumo à Lua. Suas obras, A Máquina do Tempo (1895), A Ilha do Doutor Moreau (1896), O Homem Invisível (1897), A Guerra dos Mundos (1898), exerceram grande influência nas obras subsequentes desse gênero.

$\mathrm{Na}$ década de 30, surgem filmes memoráveis e, muitos deles, baseados nas obras já citadas. Após esse período aparece um novo astro nas histórias de ficção, o computador. Wells, previu, dentre outras coisas, os bombardeios aéreos, os tanques de guerra, porém, não o computador, mas:

Dos anos 40 para cá, a maioria dos escritores conseguiu prever corretamente o impacto cada vez maior dos computadores sobre a nossa vida. No clássico "The Moon is a Harsh Mistress" (A Lua é uma Amante Ríspida), do ótimo Robert Heinlein, escrito na década dos 60 , os colonizadores lunares, em rebelião contra o governo da Terra, são aconselhados por um computador super-inteligente e falante, exatamente como em "2001: Uma Odisséia no Espaço", de Arthur C. Clarke (SABBATINI, 1996, não paginado).

Os computadores nas histórias de ficção assumem tal complexidade e sofisticação que se tornam iguais aos humanos, inclusive no que tange às emoções e sentimentos. $\mathrm{O}$ matemático Alan Turing elaborou um teste, que introduziu em seu artigo de 1950,

\footnotetext{
${ }^{2} 1^{a}$ Lei: Um robô não pode ferir um ser humano ou, por inação, permitir que um ser humano sofra algum mal. $2^{\mathrm{a}}$ Lei: Um robô deve obedecer às ordens que lhe sejam dadas por seres humanos, exceto nos casos em que tais ordens entrem em conflito com a Primeira Lei. $3^{\mathrm{a}}$ Lei: Um robô deve proteger sua própria existência, desde que tal proteção não entre em conflito com a Primeira ou Segunda Leis.
} 
"Computing Machinery and Intelligence”, que se inicia com a pergunta: é possivel ter computadores inteligentes? Para responder essa pergunta, imaginou duas salas fechadas. Uma delas continha um computador e a outra uma pessoa. Não se pode entrar nas salas, mas é possível comunicar-se com quem está lá dentro, digitando perguntas e recebendo as respostas via terminal. Quantas perguntas seriam necessárias fazer para que alguém fosse capaz de dizer em qual sala estava a máquina e em qual sala estava o humano? Se, no final do teste, o interrogador não conseguir distinguir quem é o humano, então conclui-se que o computador pode pensar. Turing concluiu seu texto afirmando que "podemos esperar que as máquinas acabarão por competir com os homens em todos os campos puramente intelectuais" (TURING, 1950, não paginado, tradução nossa) ${ }^{3}$.

O desenvolvimento da tecnologia computacional levou vários mitos de ficção científica a uma variedade de relações inimagináveis entre o humano e a máquina. $\mathrm{Na}$ atualidade, a ficção científica abrange um vasto espectro de obras, das quais é possível citar algumas, mais antigas,

(...) Frankenstein (Mary W. Shelley, 1818), Alice no País das Maravilhas (Lewis Carrol, 1865), Flatland. Uma Aventura em Muitas Dimensões (Edwin Abbot ,1884), Drácula (Bram Stoker, 1897), A Ilha (Aldous Huxley, 1962), A Descronização de Sam Magruder (George Graylord Simpson, 1997), além de várias histórias de Julio Verne (1828-1905) e best-sellers atuais sobre ficção histórica (D’AMBROSIO, 2011, p. 45).

e do presente, como Avatar, uma das últimas produções cinematográficas de James Cameron, 2009. Avatar é uma história de ficção que se passa no ano de 2154 e uma das mensagens do filme enfatiza que, caso o ser humano não restabeleça sua ligação com a natureza, passando a respeitá-la, o futuro será caótico.

As obras de ficção científica provocam questionamentos sobre vários aspectos da existência humana, tais como filosofia moral, politica e social, envolvendo questões como, por exemplo: qual o papel da sociedade; do ser humano; a evolução; qual a natureza do bem e do mal e de outras relevantes. Realidade virtual, computadores e outros temas afins estão presentes na literatura de ficção científica contemporânea.

Nas últimas décadas, as obras de ficção têm sido apontadas como um recurso didático possível para o ensino de várias disciplinas, tais como Matemática, Física, Ciências, entre outras. Uma alternativa para o ensino e aprendizagem de Matemática seria a história como fonte de pesquisa, ou, envolver o aluno com o tema em questão, a tal ponto que ele se sentisse estimulado a escrever suas próprias histórias. Vários conceitos matemáticos são bastante explorados em histórias de ficção, tais como dimensão espacial, geometria, topologia e outros.

\footnotetext{
${ }^{3}$ We may hope that machines will eventually compete with men in all purely intellectual fields.
} 
Em sua pesquisa, Silva (2014) enumera as principais contribuições da ficção para o ensino de Matemática. Aponta seu aspecto motivador, pois torna o conteúdo mais relevante e interessante, além de favorecer o desenvolvimento do conhecimento interdisciplinar ao relacionar diversas áreas da ciência. Em decorrência dessas características, outro ponto é utilizá-la como um instrumento para contextualizar a criação de problemas matemáticos.

A ficção é uma forma de narrativa que veicula ideias ficcionais de temas científicos, podendo provocar debates sobre os mesmos, potencializando, assim, a construção do conhecimento. "O conhecimento científico é 'amaciado' na narrativa ficcional" (D’AMBROSIO, 2011, p. 45, grifo do autor), pois a ficção cientifica não está sujeita aos compromissos da ciência, às provas de validação e verificação.

Para D’Ambrosio (2011, p.45)

Uma forma especial de narrativa a ser considerada é a ficção. Podemos olhar a
ficção como narrativas difundidas para as pessoas comuns através da mídia (oral,
escrita e agora digital) e ancorada na mitologia, nos contos folclóricos e até mesmo
em conhecimento científico ou, até mesmo, pseudocientífico. Além disso, a ficção
se fundamenta em grande parte nos avanços e pensamentos científicos, base da
pseudociência.

A ficção científica é um gênero dinâmico e em constante processo de mutação, despertando em nós curiosidade e, em decorrência dessas características, oferece muitas possibilidades em sala de aula. Esse sucesso, em grande parte, se deve à multiplicidade de sentidos que a imaginação desperta, sobrepondo esta ao conhecimento. Para Einstein (1950), a imaginação é mais importante que o conhecimento, pois o conhecimento é limitado e a imaginação envolve o mundo.

O ser humano é dotado de uma imaginação ímpar e age independentemente da nossa vontade. É possível que essa capacidade tenha evoluído e se tornado mais complexa com a evolução da espécie humana. Muito do material imaginado é ficcional, levando o adulto, por exemplo, a imaginar novos mundos e a criança, super-heróis. Essas fantasias criadas por nós, ou interpretadas por meio de leituras desse gênero, são provocantes e constroem mundos fantásticos. Nesse sentido, a irrealidade, que é característica da ficção, compõe a realidade sociocultural e, muitas vezes, transita do real para o irreal e vice e versa.

Sobre esse assunto questiona Umberto Eco, “mas, se a atividade narrativa está tão intimamente ligada a nossa vida cotidiana, será que não interpretamos a vida como ficção e, ao interpretar a realidade, não lhe acrescentamos elementos ficcionais?” (ECO, 1994, p.137).

A ficção cientifica e a ciência, muitas vezes, parecem se imbricar sem sabermos se uma ideia ficcional leva à produção científica ou vice-versa. É possível traduzir o empírico e o 
imaginário em contos de ficção e essa é a proposta em "Bioboy: o ciborgue que calculava", fazendo alusão ao livro de Malba Tahan, "O homem que calculava".

O objetivo do conto é de ilustrar os impactos da Cibernética e das ciências decorrentes desta na sociedade. Como Beremiz, personagem de Malba Tahan, Bioboy, personagem do conto, era o apelido do garoto que calculava. O prefixo "bio" caracteriza a natureza de seus cálculos matemáticos, que são efetuados por meio da mobilização de seus recursos biológicos, e não dos seus recursos cibernéticos. Algumas ideias cibernéticas desempenham papéis-chave no mundo de Bioboy, assombrado pelos problemas que provocamos em nosso habitat, na atualidade, e que irão refletir no século L, período em que se passa a história ficcional, no mundo de Bioboy.

Espera-se que esse conto possa ser usado por educadores como material de atividades pedagógica, objetivando a reflexão sobre os diversos conteúdos matemáticos e suas interfaces com outras áreas do conhecimento, como a Cibernética, a Física, a Filosofia, a Geologia, entre outros abordados no texto. Potencializa-se desse modo, a ficção científica como um estímulo ao ensino da Matemática dentro de um contexto dialógico.

\section{Conto de ficção científica}

\section{Bioboy: o ciborgue que calculava}

\section{Capítulo I - O estrangeiro}

Bioboy permanecia sentado e olhando tudo ao seu redor, atentamente. Não restava a menor dúvida, estava comparando tudo o que via com os registros de sua memória. Nesse transe, calculava a probabilidade de aquelas imagens serem apenas projeções de um mundo virtual. Há muito tempo isso deixou de ser um problema para os terráqueos, não para ele.

Ele era tido, por todos que o conheciam, como uma pessoa confusa e atrapalhada. Seu pai não tinha dúvidas, sua parte cibernética não funcionava bem.

- Vejam só - contava seu pai- calculamos, diariamente, tim-tim por tim-tim, tudo o que o nosso metabolismo necessita em função das atividades que realizamos. À medida que falava, sua perplexidade aumentava e o seu tom de voz também. Continuou: 
- Esse cálculo é muito simples, basta apertar um botão e pronto, tudo é calculado e registrado em nossa memória. Mas meu filho perde um tempão fazendo e refazendo esses cálculos.

Bioboy era um terráqueo diferente. Ele não se rendia às imposições do seu pai, pois o que mais gostava mesmo era formular conjecturas, procurar por padrões e valer-se de raciocínio lógico e abstrato. Assim, sua grande paixão era a Matemática.

Acho mesmo que o seu pai não entendia muito bem tudo isso. E, naquele momento em que Bioboy assistia às suas próprias ações, tentando analisar a possibilidade de ser esboço de sua própria imaginação, eis que alguém novo surgiu em cena.

- Olá - disse o estrangeiro. - Venho do outro lado, não sei quem sou nem para aonde vou, mas sei que a matriz que me gerou fez de mim um ser, um ser pensante. Bioboy o ouvia como se estivesse no mundo dos sonhos e jamais esqueceria essa conversa. O estrangeiro, entretanto, continuou a discorrer sobre a semelhança entre ele e Bioboy.

- Temos muitas coisas em comum - ponderou, ele. - Gostamos de pensar, mobilizando somente nossos recursos biológicos. E sabe por que poucas pessoas pensam como nós? - perguntou ele.

- Não - confessou Bioboy. E ele, empolgado, continuou:

- Para que isso seja possível precisamos manter nossos registros sensoriais, táteis e visuais associados, coisa incomum para os seres da nossa era.

Bioboy, ainda surpreso com a chegada inesperada daquela criatura, balbuciou:

- Desculpe, mas posso ajudá-lo em ....? - Ele mal tinha formulado a pergunta e o estrangeiro retomou a palavra, sem lhe responder.

- Como ia dizendo, há muito tempo o homem se inspirava na natureza para desenvolver novos sistemas e agora... Nesse momento, Bioboy o interrompeu com veemência, pois percebeu que só assim teria chance de falar alguma coisa.

- E a-go-ra? - Falou Bioboy indignado, acentuando a pronúncia de cada sílaba - O homem de que acabou de falar, ao mesmo tempo em que se inspirava na natureza, a destruía sem piedade! - Já mal humorado, prosseguiu com seu discurso.

- Perdura até hoje o esgotamento dos recursos naturais que eles provocaram e o rastro de destruição que semearam no planeta.

Resolveu explicitar melhor o seu ponto de vista, pois o estrangeiro começou a resmungar, parecendo não concordar com o que ele estava dizendo. 
- Já são cerca de 30.000 anos e o dióxido de carbono deixado por essa civilização ainda não se dissipou. Assim, hoje, todos os nossos consumos e movimentações são assistidos pelo survive's program.

Por alguns momentos pairou no ar um silêncio, um pouco incômodo entre eles e, nesse ínterim, Bioboy resolveu acrescentar mais uma razão pela qual a Terra quase pereceu.

- Ah! - exclamou ele, iniciando nova argumentação - Naquela época, os humanos não tinham controle sobre o aumento da população, assim os problemas ambientais se agravavam cada vez mais.

Como Bioboy adorava fazer cálculos, aproveitou o embalo e quantificou sua ideia.

- Suponha que a população humana aumente $1 \%$ a cada ano. No ano seguinte, a quantidade é 1.01 à população original, 1.0201 no segundo ano, 1.030301 no terceiro ano, e assim sucessivamente. Logo, em 70 anos ela duplicou.

- Curioso! - retrucou o estrangeiro - Esse cálculo, o quociente entre o logaritmo de dois e o logaritmo de 1.01, que resultou o valor 70, me remete a um fluxo intenso de circuitos, por exemplo, o das finanças.

- Em desuso, nos tempos atuais - replicou Bioboy - apesar de que a função logarítmica seja capaz de responder uma gama enorme de questões, tais como: epidemias, consumo de energia, explosões nucleares e demográficas.

A discussão continuou. Entre ambos havia muitas ideias em comum e uma delas a de que, hoje, o nosso maior tesouro é o equilíbrio, a harmonia, que o homem conseguiu estabelecer entre ele e a natureza, ou seja, depois de tantas intempéries, conseguimos manter o planeta habitado.

Findada a discussão, o estrangeiro pegou carinhosamente um punhado de terra e olhou-a com admiração.

- Não precisamos de muito para entender nossa evolução - disse ele. -Tenho cá, comigo, um pedaço do universo e, através desse punhadinho de terra, posso ver que o campo magnético da Terra inverteu-se centenas de vezes ao longo dos últimos bilhões de anos.

- E tem mais, ainda sugere o que está por vir! - Agora, era ele que estava empolgado, e continuou. - Por exemplo, as mudanças que estão ocorrendo no metal líquido da Terra, há 3000 quilômetros abaixo da superfície, sugerem a possibilidade de uma nova reversão do campo geomagnético do planeta.

Os dois ficaram calados por algum tempo. Era possível ouvir ao longe o desligamento da usina de energia solar, que, a cada três segundos, emitia um som cada vez mais grave, o 
qual parecia compor uma partitura musical. Bioboy tirou do bolso um pequeno aparelho, que a princípio não o reconheci, acionou-o e comentou com o estrangeiro:

- Faltam 3 minutos e 53 segundos para o pôr do sol e 3 minutos e 58 segundos para o último som da usina chegar até nós, considerada a distância que estamos dela, 1650 metros, e a velocidade das ondas sonoras no ar, que é de 330 metros por segundo.

O estrangeiro olhou mais atentamente o aparelho e exclamou:

- Nossa, que aparelho antigo!

- É um cronômetro - disse Bioboy orgulhoso - Ganhei do meu avô, que, por sua vez, ganhou do avô dele. $\mathrm{O}$ estrangeiro ficou observando o aparelho e pareceu recuar no tempo. O estrangeiro ainda estava com a mão cheia de terra e, alguns minutos depois, jogou-a para o alto e, como havia uma brisa moderada, as partículas de poeira se elevaram na atmosfera.

Os dois sorriram ao observarem o desenho traçado pelo vento com as partículas de poeira e seus pensamentos, ao sabor do mesmo vento, também tomaram outro rumo. A presença das partículas de poeira podia ser vista e sentida, mas, a cada segundo, bilhões de neutrinos atravessam nosso corpo à velocidade da luz, sem serem percebidos.

Assim como a realidade, nosso corpo também tem um forte componente aleatório que interfere em nossos pensamentos. Foi nesse rumo que, ao sabor do vento, a discussão içou as velas.

Ora o estrangeiro concordava, meneando a cabeça, ora era Bioboy que o fazia.

- O pensamento é um tipo de energia, a qual estabelece uma forte interação com as partículas de neutrinos, que se movem ao acaso - falava Bioboy. Ao que respondia, prontamente, o estrangeiro.

- Nosso cérebro funciona como um servidor de dados, recepcionando e decodificando esses pacotes de dados, inclusive os neutrinos que podem ser capturados pela corrente neural. Isso explica porque posso criar uma imagem, dar voz e pensamento a ela e imaginá-la real.

E, alternadamente, um concordava com o outro. Assim, foi se criando uma empatia entre ambos. Bioboy abaixou-se para pegar mais um punhado de terra e, quando virou, percebeu que o estrangeiro não estava mais ali. Olhou ao redor... Nada.

Ele sabia que a visualização não era o suficiente para conduzir o seu pensamento e, num sussurro, falou:

- Você pisca o olho e a luz dá sete voltas e meia em torno da Terra. Foi nesse piscar de olho que o estrangeiro desapareceu.

\section{Capitulo II - O mundo de Bioboy}


No século L, o equilíbrio estava estabelecido entre o homem e a natureza. O pai de Bioboy sempre dizia: - É preciso ordem e racionalização para vivermos em uma sociedade justa, humanista e ecologicamente responsável.

A Matemática era a chave para a realização de tudo isso. Tudo era milimetricamente calculado, desde as rações diárias, água, dejetos, lixo, etc. A racionalização de métodos e procedimentos fazia parte da vida de cada terráqueo, tornando-se essencial para a sua sobrevivência.

Por exemplo, um simples nome era capaz de identificar unicamente um terráqueo, suas potencialidades, o continente em que habitava e outras coisas mais. Assim, o próprio nome era um código e o que ele não conseguia revelar, o seu link para um chip de computador complementaria as informações.

Com relação à ordem social, esta era fundada na generosidade de todos para com todos, necessidades modestas, alta eficiência e consumo racional. Era essa a sociedade do século L, da qual Bioboy fazia parte. A vida transcorria sem grandes surpresas.

Bioboy era ainda bastante jovem e tinha toda a vida pela frente. Como havia nascido no século XLIX, tinha ainda mais dois séculos para executar sua missão. Todo mundo nascia, sempre, no primeiro dia de um século. Todo mundo deixava de existir no primeiro dia do terceiro século consecutivo ao seu nascimento. Já nasciam com uma identidade genética prédefinida, cujas aptidões seriam aperfeiçoadas, ao longo dos anos, para fins específicos e, quase sempre, em prol dos humanos.

Bioboy era um desses terráqueos e, pela sua idade, estava prestes a conhecer o motivo de ter vindo ao mundo. Quando era menor, vivia perguntando para seus botões: - Será que essa minha obsessão por cálculo tem algo a ver com a minha missão? Suas conjecturas sempre o levavam a crer que sim, mas, quando ficou um pouquinho mais velho passou a controlar melhor sua ansiedade por desvelar a missão que tinha a cumprir.

Esse não era seu nome, mas, sim, um apelido carinhoso que Vltxxkz ganhou de sua comunidade, quando ainda pequeno. - Bioboy, que apelido engraçado você tem! - exclamava um amigo. Ou então - Por que você tem esse apelido? - perguntava o outro. A explicação dele era sempre a mesma.

- É que a cada duas ideias que surgem na minha cabeça, uma delas envolve cálculos e para resolvê-los eu uso meus recursos biológicos, e não os chips eletrônicos. Então foi essa mania que lhe rendera o apelido. O tempo passou, ele cresceu e, na mesma proporcionalidade, a complexidade dos cálculos que efetuava. 
Ah! Por falar em infância, um fato marcante nessa fase da vida de Bioboy foram as histórias antigas, que lia ou ouvia. As suas preferidas eram as que iam além dos limites da compreensão, que falavam de intuição e, muitas vezes, essa palavra referia-se ao sexto sentido. Ao ouvi-las ou lê-las, sempre resmungava consigo mesmo: - Estupendamente intrigante e paradoxalmente incompreensível! E finalizava com uma pergunta: - Será que o sexto sentido da história tem algo a ver com o nosso sexto sentido? - Muito sensata sua pergunta - falavam uns e outros. Assim, ouviu muitas respostas, mas nenhuma convincente o bastante para que ele deixasse de tornar a fazê-la outras vezes.

Muitas dessas respostas falavam da mutação que o humano sofrera, há centenas de anos, relativa aos sentidos que formam o sistema somatossensorial. Os humanos adquiriram um novo sentido e, agora, possuíam esse chamado "sexto sentido" - imputado, programado e operado em silício e integrado a rede neural.

Esse novo sentido veio suprir as deficiências dos outros. Posso dar um exemplo: antes o olho humano não era capaz de ver a radiação de todos os comprimentos de onda e outras coisas mais e, agora, o sistema nervoso do homem está em constante interação com o mundo exterior, ou seja, quase tudo é perfeitamente detectável por esse novo sentido.

- Isso tudo é muito interessante - dizia Bioboy - mas eu quero mesmo entender se existe uma relação entre eles, pois, às vezes, tenho a impressão de que estamos falando da mesma coisa e, outras vezes, de coisas antagônicas.

Como vocês já perceberam, Bioboy, decididamente, não desistia tão facilmente de entender as coisas. Agora, estava prestes a tornar-se um "Hognoscom", designação dada a um humano que alcança a sabedoria suprema. Suprema porque, além de tornar-se adulto e tomar conhecimento de sua missão, seus conhecimentos serão aperfeiçoados e transformados em obra coletiva. Para isso, sua atenção à vida é redobrada.

Voltando ao caso do estrangeiro, Bioboy ainda não tinha uma explicação, isso ficou para depois. Por ora, sua atenção estava voltada para a natureza que lhe apresentava um raro fenômeno. A Lua postava-se diante do Sol e, com cuidado assaz, procurou, milimetricamente, ajustar o seu centro ao do Sol. Numa dança concêntrica, provocou um eclipse solar anular. O pano de fundo, o horizonte, cedeu aos seus caprichos, baixou à sombra para destacar a beleza do momento, um anel de luz para as Deusas das Galáxias.

\section{Capítulo III - A situação problema}


Findo o espetáculo, Bioboy suspirou e sorriu. Seu semblante espelhava o que acabara de assistir, o show da natureza. Aos poucos, sua mente foi se ocupando, novamente, do caso do estrangeiro misterioso. Começou com um simples encadeamento de ideias e, devagarinho, esse encadeamento tornou-se mais complexo. - Lógica é a ciência de raciocinar, ou seja, palavra que usamos para determinadas maneiras de relacionar ideias, não é? Foi assim, que Bioboy, começou a criar um sistema lógico para desvendar esse mistério.

Primeiro, foi resgatar da memória os dados relacionados a esse assunto, reunindo cada detalhe por mais insignificante que fosse.

Depois de alguns cálculos,

- Uma coisa é certa - resmungou ele - a radiação eletromagnética emitida pelo corpo do estrangeiro não condiz com a calculada. Sabemos que o comprimento de onda e a frequência desta são inversamente proporcionais, ou seja, conforme diminui o comprimento de onda, a frequência aumenta e também a energia que a onda é capaz de transportar.

Nada disso fazia sentido para os dados amostrados, pois o feedback eletromagnético, entre ele e o estrangeiro, eram incompatíveis com o modelo adotado, levando-o ao colapso. Outras evidências também foram incorporadas ao seu sistema lógico, como ele mesmo disse:

- O cálculo do ângulo de chegada de cada partícula de energia foi o que me deu uma resposta definitiva para essa questão. Em uma realidade virtual, a rota dos raios segue uma estrutura geométrica precisa, matricial, diferente da real, na qual eles se originam de todos os ângulos possíveis. A geometria, em conjunto com as informações anteriores, me levou à triangulação necessária para determinar com exatidão que o estrangeiro é um ser virtual.

Repetiu novamente sua conclusão, como se quisesse validá-la, e completou:

- Mas... Uhhhh! - sentiu-se arrepiado. Será um sentimento de déjà vu? - ponderou ele.

De certa forma uma parte do enigma estava resolvido. Ele sabia que a imagem do estrangeiro não era real. Certamente que tudo isso deixou o jovem Bioboy curioso e era esperado que questionasse. E foi o que fez.

- Qual o significado de tudo isso? É um teste? Tudo isso tem a ver com a minha missão? O que há a fazer?

Esta última pergunta foi dirigida a seu pai, que, naquele momento, estava por perto e respondeu prontamente:

- Existe mesmo um ponto a ser entendido. - Mas não deu nenhum palpite.

Na manhã seguinte, logo cedo, Bioboy foi até a Conexão Conhecimento. Encontrou, por lá, muitos amigos. Aliás, era quase impossível ir até lá e passar despercebido, pois a arquitetura de sua construção era projetada de tal forma que a probabilidade de as pessoas se 
encontrarem era grande. A troca de experiência entre pessoas de diferentes formações era essencial para o sucesso do aprendiz e isso justificava a arquitetura.

Como cada aprendiz escolhia suas atividades, dirigiu-se para a sala que tinha alguns simuladores. Essas simulações eram feitas em um computador que continha todas as informações digitalizadas da Terra e da galáxia. Sendo assim, era possível reconstituir um evento passado. Para falar a verdade, era como se as simulações fossem verdadeiras máquinas do tempo às quais permitiam compor o passado.

Antes de qualquer coisa, trocou algumas ideias com amigos presentes, os quais the deram algumas sugestões. Disse um:

- Olha, a primeira etapa será explorar o seu mundo sensorial.

- Não concordo - argumentava o outro.

Alguém, no meio das discussões, sugeriu:

- A transferência de informações da mente para o chip de computador não irá ajudar muito. Se você olhar para o corpo humano, há milhares de milhões de células, cada uma tem suas funções próprias, a sua própria energia, e todas funcionam harmoniosamente.

O fato é que essa última ideia despertou outra na cabeça de Bioboy, pois, sorrindo, disse:

- É isso mesmo - e repetiu a última frase - e todas funcionam harmoniosamente juntas.

Findada a discussão, começou a programar o computador para a simulação. A primeira fase consistia em parametrizar o simulador e conectar-se à máquina, já que a sua mente seria um dos dispositivos de input. À sua frente, ficava um painel de luzes coloridas, onde cada cor indicava uma funcionalidade diferente. Na parte superior esquerda, luz azul, indicava as entradas de dados e era possível observar as opções por ele assinaladas: para banco de dados, cérebro; para transistores, neurônios. Ou seja, suas sinapses seriam transferidas para o computador, codificadas e transformadas em informações e estas podiam intervir de modo efetivo no processamento das informações.

$\mathrm{Na}$ parte inferior esquerda, luz vermelha, ficavam os dispositivos de saída. Na opção assinalada figurava seu nome, Vltxxkz, sinal que a saída seria registrada na sua memória. Complementou com outros dispositivos de entrada, informou parâmetros e, sempre muito cauteloso, especificou um alto grau de confiabilidade, $99 \%$.

$\mathrm{Na}$ parte central do painel de controle, luz amarela, era possível observar, pelo ícone luminoso, o programa simulador selecionado. Dentre vários, o selecionado era um dos mais precisos, considerava todas as situações que estão relacionadas, criando matrizes de várias 
dimensões que interagem até compor uma linguagem coerente e que represente a compreensão do problema. Com o objetivo de compor relações, realiza inferências, considerando tanto o conhecimento implícito, conhecimento piloto fornecido pela memória de Bioboy, quanto o explicito, conhecimento armazenado explicitamente, ou seja, em alguma forma de mídia.

Depois que informou todos os parâmetros, Bioboy falou:

- De certa forma, a proposta é encontrar conexões não triviais, sendo assim, tenho que me livrar de todas as hipóteses passíveis de erro, para daí, então, procurar as soluções prováveis buscando padrões reveladores. A Matemática também é um modo de pensar e pode ajudar-me a encontrá-lo. Dito isso, sentou no computador e deu início à simulação.

\section{Capítulo IV - A simulação}

"Muitas vezes sonhamos e pensamos estar vivendo uma experiência real e, quando acordamos, muitas vezes, confusos e sonolentos, procuramos um referencial para saber se o vivido foi um sonho ou aconteceu de fato. A sensação experimentada nas simulações é a mesma. Buscam-se referenciais de forma que se possa entender um fenômeno ocorrido na vida real".

Foram exatamente essas as palavras utilizadas por Bioboy ao fazer alguns comentários, quando terminou a simulação. E continuou, expondo seu ponto de vista:

- Como em um sonho, o referencial é importante para discernir a realidade e também o é na simulação. O simples fato de mudar algo que possa parecer insignificante no referencial pode ter consequências imprevisíveis e mudar todo o contexto. A interpretação da mensagem está diretamente relacionada com o contexto. Como por exemplo, o DNA pode transmitir sinais diferentes em contextos diferentes.

Depois de passar toda a tarde no simulador, ele tinha uma resposta para o seu enigma e esse foi o assunto da Conexão Conhecimento, durante o resto da noite. Essa simulação teve um colorido especial para Bioboy, pois ele conseguiu formular uma audaciosa interpretação do real fundamentada em base lógica e matematicamente sólida. Foi assim que Bioboy entendeu a aparição do estrangeiro e a configuração de sua mente. Riu de ter sido tão ingênuo e não reconhecer sua assinatura virtual, o estrangeiro.

No dia seguinte, Bioboy acordou demasiadamente cedo. Através da janela, semiaberta, podia vislumbrar o objeto mais brilhante do firmamento. Deu um salto e pôs-se de pé para contemplar melhor aquela beleza. $\mathrm{O}$ ar límpido propiciava uma visão extremamente reluzente 
de Vênus, cuja magnitude parecia ultrapassar em muito os seus -4.4. Seu olhar estava fixado em algum lugar além do infinito, pensando nas experiências do dia anterior.

A notícia correu. Logo cedo, na Conexão Conhecimento, havia várias pessoas aguardando a chegada de Bioboy. Ele foi um dos primeiros a chegar, esperou alguns minutos e deu inicio a explicação:

- A Matemática explica o que não podemos ver. De certa forma, há uma dose de magia quando os controles fogem de nossos sentidos e a Matemática assume o comando.

Foi assim que começou seu discurso, respirou profundamente e continuou:

- Jamais passou pela minha cabeça que o estrangeiro pudesse ser minha assinatura digital ou minha antimatéria. Tal descoberta se deve ao sinal negativo numa equação que surgiu em uma situação de grande complexidade durante a simulação.

O estrangeiro, como ser virtual, pode mover-se lateralmente no tempo, ou seja, transitar do passado para o futuro e vice-versa. Quando se está avançando no tempo, do passado para futuro, a criação vem antes da destruição e, em caso contrário, do futuro para o passado, a criação vem depois da destruição.

Olhou para as pessoas como se esperasse uma intervenção e, como ninguém se manifestasse, continuou:

- Todos nós temos uma missão e na minha, seja ela qual for, a Matemática está envolvida. $\mathrm{O}$ estrangeiro veio avaliar minha capacidade lógica para resolver problemas e o meu conhecimento matemático, ou seja, ele veio constatar se estou apto para tornar-me um Hognoscon. É o principal objetivo da missão do estrangeiro.

No trânsito do futuro para o passado, ele constatou que a maior deficiência da raça humana é que ela está perdendo, ao longo do tempo, suas capacidades criativa, de raciocínio lógico, de abstração e outras mais. Essa perda é devida ao intenso uso eletrônico. Em decorrência disso, a Matemática está se afastando da experiência humana de uma forma tão abrupta, que estava mudando a maneira de funcionamento de nosso cérebro.

Não resta dúvida que, sem a Matemática, seria impossível desenvolver novos recursos tecnológicos capazes de potencializar nossas limitações biológicas. Sem esses recursos, não conseguiríamos sobreviver. Podemos afirmar, sem titubear, que a matemática governa o mundo.

Alguém da plateia pediu a palavra. Era o mestre da Conexão Conhecimento. Começou falando sobre a missão de Bioboy:

- A missão de Bioboy começa hoje, aqui na Conexão Conhecimento. Bioboy está pronto. Como ele mesmo disse, a missão do estrangeiro era avaliar sua capacidade e posso 
afirmar que, ao desvendar essa charada, Bioboy o fez com inteligência e criatividade. Quero parabenizá-lo pela lógica que balizou sua interpretação e pela beleza geométrica que deparou ao expandir as dimensões matriciais para associar as duas realidades díspares: virtual e real. Há muito tempo que nós, terráqueos, canalizamos todo o conhecimento para garantir nossa sobrevivência. Bioboy vai trabalhar para esse fim e tenho certeza que o fará da melhor maneira. Quero convidar a todos os presentes para o seu Hognoscere que será realizado amanhã.

Finalizou seu discurso com esse convite.

No dia seguinte, terça-feira, 10 de julho de 4910. Dia especial para Bioboy. Havia festa na Conexão Conhecimento que ficava na pequena comunidade onde morava, uma dentre muitas outras espalhadas por toda a galáxia. Todas elas estavam conectadas para assistir e homenagear Bioboy pelo seu Hognoscere. Os homenageados eram agraciados com a estatueta "Arquitetos do Futuro", na qual se podia observar a espiral de Fibonacci, representando a galáxia como se fosse um furacão e, emergindo do seu centro, um terráqueo que vence sua fúria com seu conhecimento.

Para mim, como narrador e integrante dessa comunidade, é sempre um momento extraordinário assistir a essas festividades, nas quais, meninos como Bioboy, tornam-se homens imprescindíveis para a ciência. Sempre que narro essas histórias, reflito sobre a nossa natureza, nossos valores, nossos devires e nossos fins. Apesar de não ser totalmente uma criatura humana, mas em grande parte, uma construção matemática, sempre me emociono ao narrá-las. O fim da história não é difícil de imaginar e as palavras que se seguem foram pronunciadas por Bioboy no dia do seu Hognoscere:

“O estado do mundo, no momento presente, determina precisamente a maneira como o futuro se desenrolará. A minha missão, que se inicia hoje, é justamente preservar algumas funcionalidades do cérebro humano que, se nada for feito, desaparecerão em um futuro próximo. O processo de projetar o homem para além de sua natureza biológica, tornando-o um ser programável, levou o a desligar-se de sua natureza humana. O meu desafio é reestabelecer essa conexão no que tange à capacidade de raciocínio matemático, sem o qual o humano perderá a supremacia sobre seu corpo, lugar dos sentidos e experiências. Sei que são inumeráveis os estratagemas da evolução, mas sei, também, que é necessário interagir para corrigir um erro do passado. Não temos tempo para esperar a seleção natural resolvê-lo e, sendo assim, resolvê-lo-emos utilizando as mesmas tecnologias que o originaram. Ser um Hognoscere significa reconhecer a minha capacidade de transformar, usar meu conhecimento 
em prol da humanidade e meu aporte, a Matemática, servirá para humanizar o homo silicium. Assim espero".

Bioboy, o ciborgue que calculava.

\section{Referências}

BRANTLINGER, P. The Gothic Origins of Science Fiction. Durham: Duke University Press, v. 14, n. 1 , p. $30-43,1980$.

D’AMBrosio, U. EA, Pitágoras e Avatar: cenários distintos em Matemática. ed. 1. São Paulo: Arte Livros Editora Ltda, 2011.

ECO, U. Seis passeios pelos bosques da ficção. Tradução Hildegard Feist. ed 2. São Paulo: Cia. das Letras, 1994.

EINSTEIN, A. Out of My Later Years. ed 1. New York: The Philosophical Library, 1950.

PIASSI, L. P.; PIETROCOLA, M. Ficção científica e ensino de ciências: para além do método de 'encontrar erros em filmes'. Educação e Pesquisa, São Paulo, v. 35, n. 3, p. 525-540, set./dez. 2009. Disponível em: < http://www.scielo.br/pdf/ep/v35n3/08.pdf >. Acesso em: 04 jan. 2014.

SABBATINI, R.M.E. Ficção Científica e Computadores. Correio Popular, Campinas, 1996.

Disponível em: < http://www.renato.sabbatini.com/correio/corr9625.htm>. Acesso em: 04 jan. 2014.

SILVA, L. M. A FICÇÃO E O ENSINO DA MATEMÁTICA: análise do interesse de estudantes em resolver problemas. 2014. 207 f. Tese (Mestrado de Educação em Ciências e Matemática) Pontifícia Universidade Católica, Porto Alegre, 2014. Disponível em: <http://repositorio.pucrs.br/d space/bitstream/10923/6686/1/000459164-Texto\%2bCompleto-0.pdf>. Acesso em: 12 nov. 2017.

TURING, A. M. Computing machinery and intelligence. Mind, Oxford, n. 59, p. 433-460, 1950. Disponível em: <http://www.csee.umbc.edu/courses/471/papers/turing.pdf >. Acesso em: 08 jan. 2014.

Submetido em 05 de Junho de 2017. Aprovado em 19 de Dezembro de 2017. 